\title{
Acute Toxicity of 4-Nonylphenol to Aquatic Invertebrates in Taiwan
}

\author{
L. Hong $\cdot$ M.-H. Li
}

Received: 13 October 2006/ Accepted: 5 April 2007/Published online: 10 July 2007

(C) Springer Science+Business Media, LLC 2007

\begin{abstract}
Acute toxicity of 4-nonylphenol (NP) was examined in six freshwater species from three phyla platyhelminthes, arthropoda and mollusca. Values of the 48-hour $\mathrm{LC}_{50}$ of NP for six species ranged from 20 to 508 $\mathrm{ug} / \mathrm{L}$ and values of the 96 -hour $\mathrm{LC}_{50}$ for four species ranged from 120 to $457 \mathrm{ug} / \mathrm{L}$. The most sensitive species tested was a water flea, Ceriodaphnia cornuta, with a 48hour $\mathrm{LC}_{50}$ of $20 \mu \mathrm{g} / \mathrm{L}$. The no observed adverse effect level (NOAEL) and lowest observed adverse effect level (LOAEL) values of NP found were in the range of $<10$ to 400 $\mu \mathrm{g} / \mathrm{L}$ and 10 to $450 \mu \mathrm{g} / \mathrm{L}$ after 48 hours of exposure, respectively.
\end{abstract}

Keywords 4-nonylphenol - Freshwater planarian .

Water flea · Freshwater shrimp · Freshwater snail .

NOAEL $\cdot$ LOAEL $\cdot \mathrm{LC}_{50}$

4-Nonylphenol (NP) is widely used in producing nonionic surfactants, such as nonylphenol ethoxylates (NPEs), for detergents, emulsifiers, pesticides, lubricants, and oil additives in our daily life (Ying et al., 2002). On the other hand, NP is also a breakdown product of NPEs that are commonly discharged in large quantities by sewage treatment plants or directly into the aquatic environment in areas where there is no sewage treatment. Consequently, NPEs and their degradation products, especially NP, have been found worldwide in wastewater discharges, sewage treatment plant effluents, natural water, and sediments (Bennie, 1999; Ying et al., 2002). Because NP and NPEs

L. Hong · M.-H. Li ( $\square)$

Environmental Toxicology Laboratory,

Department of Geography, National Taiwan University, 1,

Section 4, Roosevelt Road, Taipei 106 Taiwan, ROC

e-mail: meihuili@ntu.edu.tw are ubiquitous, persistent, and easily bioaccumulated, potential toxic effects of these chemicals have attracted much research attention in the last few years. Previous investigations have shown that NP was estrogenic (Nimrod and Benson, 1996) and highly toxic to aquatic animals both acutely and chronically (Lussier et al., 2000; Staples et al., 2004). In addition, NP appeared to have reproductive and developmental effects to both vertebrates (Nimrod and Benson, 1998) and invertebrates (Nice et al., 2000; Tanaka and Nakanishi, 2002).

NPEs and NP are one of the major classes of nonionic surfactants that have been widely used and produced in Taiwan. According to the Taiwan Environmental Protection Administration, NPEs/NP encompassed about $80 \%$ of the annual nonionic surfactants market in Taiwan, and two major industrial producers, China Man-Made Fiber Corporation and Formosan Union Chemical Corporation, were estimated to produce about 16,000 tons of NP annually (Taiwan EPA, 2005a). Several studies have been conducted to analyze NPEs and/or NP concentrations in river waters of Taiwan in the past decade (Ding et al., 1999; Wang et al., 2001; Cheng et al., 2006). In fact, the concentrations of NP presented in the rivers of Taiwan were usually higher than the values reported in the other countries (Cheng et al., 2006). However, very little data exists on the toxicity of NP to aquatic organisms in Taiwan.

In this study, we selected six freshwater species to evaluate the acute toxicity for NP. These aquatic invertebrates were chosen as study species because of their widespread presence in the rivers and/or lakes of Taiwan as well as other parts of the world. The objective of this study was to examine the acute toxicity of NP to aquatic invertebrates that occur widely in the aquatic environment of Taiwan. The results of this study can provide some useful information about the acute toxicity of NP to some aquatic 
animals in Taiwan and help to assess the potential effects of NP in subtropical and tropical aquatic ecosystems.

\section{Materials and Methods}

4-Nonylphenol (CAS no. 84852-15-3) was purchased from Riedel-de Haën (Sigma-Aldrich, USA), with a chemical purity of $94 \%$. High-performance liquid chromatography (HPLC)-grade acetone was purchased from Mallinckrodt. $\mathrm{NP}$ was dissolved in acetone and the test solution was replaced every other day to maintain treatment concentrations. In order to eliminate the risk of leached potential endocrine disruptors, plastic materials were avoided in all aquaria and plumbing. Dechlorinated tap water was stored in a stainless-steel tank before use. All animals were kept in different sizes of glass beakers or stainless-steel containers in our laboratory.

Planarians (Dugesia japonica) were collected from the Nanshi stream located in Wulai, in the Taipei prefecture, Taiwan in 2004. Since then, the planarians have been maintained in dechlorinated tap water in our laboratory. Animals were fed raw chicken liver once a week. Culture medium was renewed after weekly feeding. Red cherry shrimps (Neocaridina denticulate) were collected from the Pingguang stream located in the Guangxing borough of the Taipei prefecture, Taiwan in April of 2006. Freshwater snails (Physa acuta) were collected from a ditch located in Shilin in Taipei City in June 2005. Snails were fed with lettuce and half of the culture medium was changed with dechlorinated water every two weeks. Water fleas (Ceriodaphnia cornuta) were collected from the campus lake of National Taiwan University in May 2006. In addition, the other test animals, including atyid shrimps (Caridina pseudodenticulata) and water fleas (Moina macrocopa), were all purchased from local suppliers. Both water fleas were fed with algal powder twice a day and half of the medium was renewed with dechlorinated water once a week. As for the two species of freshwater shrimps, they were fed commercial fry food T850S from the Hai Feng feed company and half of their culture medium was renewed with dechlorinated water every two weeks.

Acute toxicity tests on shrimps and water fleas were performed according to the Taiwan EPA standard protocol (Taiwan EPA, 2005b) and the Organisation for Economic Co-operation and Development (OECD) test guideline 202 (OECD, 1984) with slight modifications, respectively. In brief, test animals were exposed to NP at five to seven concentrations or to acetone alone at a nominal concentration of $1,000 \mathrm{ppm}$ as a solvent control. All acute toxicity experiments were conducted in a temperature incubator at $28 \pm 2^{\circ} \mathrm{C}$ without illumination. For each concentration, five animals were kept in $50 \mathrm{ml}$ of test solution in a glass beaker for planarians (body length $0.7 \mathrm{~cm}$ ), freshwater snails (shell length $<0.1 \mathrm{~cm}$ ), and water fleas (younger than 24 hours) or in $1,000 \mathrm{ml}$ of test solution in a glass beaker for shrimps (body length $1.5 \mathrm{~cm}$ ). Each treatment was replicated five times during the experiments. The animals were not fed and were inspected every 24 hours for mortality during the entire 96-hour experimental period; we refreshed the medium with the same concentration at the $48^{\text {th }}$ hour. Organisms without detectable movement were considered dead and removed from the test solution.

The concentrations that were lethal to $50 \%$ of the organisms $\left(\mathrm{LC}_{50}\right)$ to each species for $24,48,72$, or 96 hours were calculated using probit analysis where possible, and trimmed Spearman-Karber analysis when conditions for probit analysis were not met (Hamilton et al., 1977). Probit analyses were made using the Probit Program (version 1.5) and trimmed Spearman-Karber analyses with trimmed Spearman-Karber program (version 1.5); both programs were obtained from the environmental monitoring systems laboratory (USEPA, Cincinnati, Ohio). The LOAEL (the lowest concentration producing animal mortality significantly different from the controls) and NOAEL (the highest concentration producing no mortality significantly different from the controls) were determined by Dunnett's multiple comparison procedure (USEPA, 1989) using the Minitab statistical program (version 13.2).

\section{Results and Discussions}

In this study, the most sensitive freshwater species was a water flea, Ceriodaphnia cornuta, with a 48 -hour $\mathrm{LC}_{50}$ of $20 \mu \mathrm{g} / \mathrm{L}$, and the species least sensitive to NP toxicity was a planarian, Dugesia japonica, with a 48-hour $\mathrm{LC}_{50}$ of 508 $\mu \mathrm{g} / \mathrm{L}$ and a 96 -hour $\mathrm{LC}_{50}$ of $457 \mu \mathrm{g} / \mathrm{L}$ (Table 1). Compared with the published data on the acute toxicity of NP, the 48hour $\mathrm{LC}_{50}$ of $20 \mu \mathrm{g} / \mathrm{L}$ found for Ceriodaphnia cornuta in our study is at the low end of the range, which is from 20 to $3,000 \mu \mathrm{g} / \mathrm{L}$ for invertebrates, as cited in Servos (1999). Acute toxicity tests with NP showed that crustaceans were the most sensitive organisms with reported 96-hour $\mathrm{LC}_{50}$ values of 20.6 and $69 \mu \mathrm{g} / \mathrm{L}$ in the amphipod Hyalella azteca, and the cladoceran Ceriodaphnia dubia, respectively (Jumel et al., 2002). In addition, 48-hour $\mathrm{LC}_{50}$ values of 190 and $67 \mu \mathrm{g} / \mathrm{L}$ were reported for Daphnia magna (Comber et al., 1993), and Daphnia galeata (Tanaka and Nakanishi, 2002), respectively. Therefore, the estimated 48-hour $\mathrm{LC}_{50}$, of $20 \mu \mathrm{g} / \mathrm{L}$ for Ceriodaphnia cornuta is considerably lower than published $\mathrm{LC}_{50}$ values for other water fleas. This suggests that the cladoceran Ceriodaphnia cornuta is relatively sensitive to NP exposure compared with other widely researched cladocerans. Indeed, this observation is also in good agreement with findings of Do 
Table $1 \mathrm{LC}_{50}(\mu \mathrm{g} / \mathrm{L})$ from 24 to 96 hours for different aquatic invertebrates exposed to NP

\begin{tabular}{|c|c|c|c|c|}
\hline \multirow[t]{2}{*}{ Species } & \multicolumn{4}{|l|}{$\mathrm{LC}_{50}(\mu \mathrm{g} / \mathrm{L})$} \\
\hline & 24 hours & 48 hours & 72 hours & 96 hours \\
\hline Dugesia japonica & $525(506-539)^{\mathrm{a}}$ & $508(419-569)^{\mathrm{a}}$ & $463(408-458)^{\mathrm{a}}$ & $457(400-451)^{\mathrm{a}}$ \\
\hline Physa acuta & $>750$ & $319(225-484)^{\mathrm{a}}$ & $128(81-182)^{\mathrm{a}}$ & $120(73-171)^{\mathrm{a}}$ \\
\hline Neocaridina denticulate & $431(352-608)^{\mathrm{a}}$ & $371(290-528)^{\mathrm{a}}$ & $252(204-311)^{\mathrm{a}}$ & $220(89-390)^{\mathrm{a}}$ \\
\hline Caridina pseudodenticulata & $>500$ & $366(292-459)^{\mathrm{b}}$ & $211(138-266)^{\mathrm{a}}$ & $195(146-259)^{\mathrm{b}}$ \\
\hline Moina macrocopa & $>500$ & $104(78-139)^{\mathrm{b}}$ & - & - \\
\hline Ceriodaphnia cornuta & $26(21-31)^{\mathrm{a}}$ & $20(16-23)^{\mathrm{a}}$ & - & - \\
\hline
\end{tabular}

${ }^{a}$ Determined using probit analysis and values in parentheses are $95 \%$ confidence intervals

b Determined using Trimmed Spearman-Karber analysis and values in parentheses are $95 \%$ confidence intervals

Hong et al. (2004). They found that Ceriodaphnia cornuta was more sensitive than Daphnia magna to acute toxicity of potassium dichromate, diazinon, methyl parathion, and mercury. Since Ceriodaphnia cornuta is a widely distributed tropical species and an easily cultivable organism, it may be suitable for use in ecological toxicity testing in tropical and subtropical aquatic environments.

According to the literature, the actual test water NP concentrations have been reported to be approximately $1 / 2$ $1 / 3$ of the nominal concentration after 48 hours (Gray and Metcalfe, 1997; Kinnberg et al., 2000). This might be helpful to explain why the $\mathrm{LC}_{50}$ values between 48 and 72 hours is disproportionably greater than $\mathrm{LC}_{50}$ values in the other 24-hour periods in freshwater shrimps and snails under our 48-hour test-medium renewal scheme. In addition, the aquatic juvenile snail, Physa acuta, had a rather high sensitivity to NP with a 96-hour $\mathrm{LC}_{50}$ of $120 \mu \mathrm{g} / \mathrm{L}$. The $\mathrm{LC}_{50}$ result for juvenile Physa acuta was much lower than the $\mathrm{LC}_{50}$ values of other mollusks reported in literature. For example, 96-hour $\mathrm{LC}_{50}$ values of 774 and 3,000 $\mu \mathrm{g} / \mathrm{L}$ were reported for an adult snail (Physella virgata) (Brooke 1993, as cited in Servos, 1999) and for an adult mussel (Mytilus edulis) (Granmo et al., 1989) exposed to $\mathrm{NP}$, respectively. One possible explanation for the increased sensitivity of Physa acuta to NP may be that a juvenile snail would not be able to enclose its body completely and thus protect itself against NP exposure. On the other hand, freshwater shrimps appeared to be less sensitive than cladocerans. Two species of freshwater shrimps tested had very similar 96-hour LC $_{50}$ values of 220 and 195 $\mu \mathrm{g} / \mathrm{L}$ for Neocaridina denticulate, and Caridina pseudodenticulata, respectively. These were in a similar range of reported acute toxicity to NP as other marine shrimps. For example, 96-hour $\mathrm{LC}_{50}$ values of 300 and $59.4 \mu \mathrm{g} / \mathrm{L}$ were reported for a marine shrimp (Crangon septemspinosa) (McLeese et al., 1980), and a grass shrimp (Palaemonetes vulgaris) (Lussier et al. 2000), respectively. This suggests that freshwater shrimps have intermediate sensitivity to NP among the aquatic invertebrate species tested. Overall our
$\mathrm{LC}_{50}$ results for NP obtained from the six aquatic invertebrates tested are in a similar range to the published $\mathrm{LC}_{50}$ of NP for aquatic invertebrates.

Freshwater concentrations of NP have been reported to be in the range of $<0.01$ to $180 \mu \mathrm{g} / \mathrm{L}$ and the average concentrations of NP are usually less than $10 \mu \mathrm{g} / \mathrm{L}$ (Bennie, 1999). In recent years, a number of research projects supported by the Taiwan Environmental Protection Administration have focused on the occurrence of NP in the rivers of Taiwan. In the 40 rivers of Taiwan, NP was detected in $54.2 \%$ of water samples with average concentrations of $4.87 \mu \mathrm{g} / \mathrm{L}$, in the range of 0.89 to $50.0 \mu \mathrm{g} / \mathrm{L}$ (Wang et al., 2001). Cheng et al. (2006) measured the concentrations of NP in 18 major rivers and also found that average NP concentrations in rivers ranged from 0.7 to $5.1 \mu \mathrm{g} / \mathrm{L}$ in 2000. In 2003, NP was found in $100 \%$ of the Kaoping River water samples with concentrations ranging from 0.19 to $183.4 \mathrm{ug} / \mathrm{L}$ (Taiwan EPA, 2005a). In the same year, NP was also measured in seven other rivers, including Lanyang River, Houlung River, Taichia River, Wu River, Yanshuei River, Bajhang River, and Fongshan River, at concentrations ranging from undetected to $1992 \mu \mathrm{g} / \mathrm{L}$ (Taiwan EPA, 2005a). The NP analytical results of the aquatic environment showed a wide variation in measured NP levels depending on the human activities and locations of the measurement in Taiwan.

In relation to ecological effects of measured NP levels and what they indicate about the magnitude of environmental damages, the risk assessment defines the predicted no-effect concentration (PNEC), which is based on standard toxicity data on $\mathrm{LC}_{50}$ or NOAEL with the application of a safety factor, can be used to evaluate possible ecological effects. The NOAEL values of NP found in this study were in the range of $<10$ to $400 \mu \mathrm{g} / \mathrm{L}$ (Table 2). If we used NOAELs divided by a safety factor of 10 to calculate PNECs, the PNECs of NP were determined to be in the range of $<1$ to $40 \mu \mathrm{g} / \mathrm{L}$ based on the results of this study. In fact, the measured NP concentrations of Taiwan river waters are still higher than the range of the 
Table 2 NOAEL $(\mu \mathrm{g} / \mathrm{L})$ and LOAEL $(\mu \mathrm{g} / \mathrm{L})$ based on mortality determined using Dunnett's test for different aquatic invertebrates exposed to NP after 48 and 96 hours exposure

\begin{tabular}{|c|c|c|c|c|}
\hline \multirow[t]{2}{*}{ Species } & \multicolumn{2}{|l|}{48 hours } & \multicolumn{2}{|l|}{96 hours } \\
\hline & $\begin{array}{l}\text { NOAEL } \\
(\mu \mathrm{g} / \mathrm{L})\end{array}$ & $\begin{array}{l}\text { LOAEL } \\
(\mu \mathrm{g} / \mathrm{L})\end{array}$ & $\begin{array}{l}\text { NOAEL } \\
(\mu \mathrm{g} / \mathrm{L})\end{array}$ & $\begin{array}{l}\text { LOAEL } \\
(\mu \mathrm{g} / \mathrm{L})\end{array}$ \\
\hline Dugesia japonica & 400 & 450 & 250 & 400 \\
\hline Physa acuta & 100 & 250 & 50 & 100 \\
\hline $\begin{array}{l}\text { Neocaridina } \\
\text { denticulate }\end{array}$ & 250 & 350 & 250 & 350 \\
\hline $\begin{array}{l}\text { Caridina } \\
\quad \text { pseudodenticulata }\end{array}$ & 100 & 250 & 100 & 250 \\
\hline Мoina macrocopa & 50 & 100 & $\longrightarrow$ & $\longrightarrow$ \\
\hline $\begin{array}{l}\text { Ceriodaphnia } \\
\text { cornuta }\end{array}$ & $<10$ & 10 & - & - \\
\hline
\end{tabular}

PNECs for NP. Therefore, an environmental risk due to NP is expected to exist in the aquatic environment of Taiwan. Currently, the Taiwan Environmental Protection Administration is considering including NP on the list of the Toxic Chemical Substances Control Act to restrict its use. Nevertheless, historical and existing use of NP/NPEs is likely to result in elevated and ecologically significant levels of NP in a significant proportion of Taiwan rivers and these NP concentrations can be expected to stay at significant levels for a number of years after cessation of its use.

To our knowledge, this is the first study to report $\mathrm{LC}_{50}$ values of NP for these six aquatic invertebrates tested in Taiwan. Based on the results of this study, NP in river water has a potentially harmful impact on the aquatic environment of Taiwan. Moreover, the potential of NP for endocrine disruption at even lower concentrations may cause further concerns for aquatic fauna. Information on the toxicological effects of NP on aquatic fauna of Taiwan and additional investigations into NP concentrations in different aquatic environments are warranted to provide relevant data to assess the ecological risk of NP adequately. Furthermore, the uses of NP/NPEs in Taiwan should be managed to minimize their ecological impact on aquatic ecosystems.

\section{References}

Bennie DT (1999) Review of the environmental occurrence of alkylphenols and alkylphenol ethoxylates. Water Qual Res J Canada 34:79-122

Brooke LT (1993) Acute and chronic toxicity of nonylphenol to ten species of aquatic organisms. Report to the US EPA for Work Assignment No.02 of Contract No. 68-C1-0034. Lake Superior Research Institute, University of Wisconsin-Superior, Superior, WI
Cheng CY, Wu CY, Wang CH, Ding WH (2006) Determination and distribution characteristics of degradation products of nonylphenol polyethoxylates in the rivers of Taiwan. Chemosphere 65:2275-81

Comber M, Williams T, Stewart K (1993) The effects of nonylphenol on Daphnia magna. Water Res 27:273-276

Ding WH, Tzing SH, Lo JH (1999) Occurrence and concentrations of aromatic surfactants and their degradation products in river waters of Taiwan. Chemosphere 38:2597-2606

Do Hong LC, Becker-Van Slooten K, Tarradellas J (2004) Tropical ecotoxicity testing with Ceriodaphnia cornuta. Environ Toxicol 19:497-504

Granmo A, Ekelund R, Magnusson K, Berggren M (1989) Lethal and sublethal toxicity of 4-nonylphenol to the common mussel (Mytilus edulis L.). Environ Poll 59:115-127

Gray MA, Metacalfe CD (1997) Induction of testis-ova in Japanese medaka (Oryzias latipes) exposed to $p$-nonylphenol. Environ Toxicol Chem 16:1082-1086

Hamilton MA, Russo RC, Thurston RV (1977) Trimmed SpearmanKarber method for estimating median lethal concentrations in toxicity bioassays. Environ Sci Technol 11:714-719

Jumel A, Coutellec MA, Cravedi JP, Lagadic L (2002) Nonylphenol polyethoxylate adjuvant mitigates the reproductive toxicity of fomesafen on the freshwater snail Lymnaea stagnalis in outdoor experimental ponds. Environ Toxicol Chem 21:1876-1888

Kinnberg K, Korsgaard B, Bjerregaard P, Jespersen A (2000) Effects of nonylphenol and $17 \beta$-estradiol on vitellogenin synthesis and testis morphology in male platyfish Xiphopjorus maculates. J Exp Biol 203:171-181

Lussier SM, Champlin D, LiVolsi J, Poucher S, Pruell RJ (2000) Acute toxicity of para-nonylphenol to saltwater animals. Environ Toxicol Chem 19:617-621

McLeese DW, Zitko V, Metcalf CD, Sergeant DB (1980) Lethality of aminocarb and the components of the aminocarb formulation to juvenile Atlantic salmon, marine invertebrates and a freshwater clam. Chemosphere 9:79-82

Nice HE, Thorndyke MC, Morritt D, Steele S, Crane M (2000) Development of Crassostrea gigas larvae is affected by 4nonylphenol. Mar Pollut Bull 40:491-496

Nimrod AC, Benson WH (1996) Environmental estrogenic effects of alkylphenol ethoxylates. Crit Rev Toxicol 26:335-364

Nimord AC, Benson WH (1998) Reproduction and development of Japanese medaka following an early life stage exposure to xenoestrogens. Aquat Toxicol 44:141-156

OECD (1984) OECD Guideline for testing of chemicals 202 Daphnia sp, acute immobilization test and reproduction test. Paris, France

Servos MR (1999) Review of the aquatic toxicity, estrogenic responses and bioaccumulation of alkylphenols and alkylphenol polyethoxylates. Water Qual Res J Canada 34:123-177

Staples C, Mihaich E, Carbone J, Woodburn K, Klecka G (2004) A weight of evidence analysis of the chronic ecotoxicity of nonylphenol ethoxylates, nonylphenol ether carboxylates, and nonylphenol. Hum Ecol Risk Assess 10:999-1017

Taiwan EPA (2005a) Handling management including restricted uses for toxic chemical substances such as polychlorinated biphenyls as announced in the list of 161 regulatory control numbers revision draft. October, 2005. Taiwan Environmental Protection Administration, Executive Yuan, ROC (in Chinese)

Taiwan EPA (2005b) Standard guide for conducting acute tests: Static renewal test for Neocaridina denticulate. NIEA B905.11B. Taiwan Environmental Protection Administration, Executive Yuan, ROC (in Chinese)

Tanaka Y, Nakanishi J (2002) Chronic effects of p-nonylphenol on survival and reproduction of Daphnia galeata: multigenerational life table experiment. Environ Toxicol 17:487-492 
USEPA (1989) Dunnett's procedure in the analysis of data from short-term toxicity tests with aquatic organisms, version 1.1. USEPA, Cincinnati, OH

Wang CH, Chang SP, Huang RK, Lee YH, Wang SK, Hung WT, Chen PS (2001) Residues survey of nonylphenol and its biological effect on male carp. Taiwan J Public Health 20:202-215

Ying GG, Williams B, Kookana R (2002) Environmental fate of alkylphenols and alkylphenol ethoxylates- a review. Environ Int 28:215-226 